\title{
Practice in Teaching and Learning of Invertebrates: Evaluating the Effectiveness of Pedagogical Language Strategies in Tanzania Secondary Schools
}

\author{
Opanga David ${ }^{1,2^{*}}$, Nsengimana Venuste ${ }^{3}$ \\ ${ }^{1}$ African Centre of Excellence for Innovative Teaching and Learning Mathematics and Science, College of Education (UR-CE), \\ University of Rwanda, RWANDA \\ 2 St John's University of Tanzania, TANZANIA \\ ${ }^{3}$ College of Education (UR-CE), Department of Mathematics, Science and Physical Education, University of Rwanda, RWANDA
}

Received 21 October 2020 - Accepted 30 December 2020

\begin{abstract}
Teaching and learning of invertebrate systematic require effective pedagogical language strategies since the terms used are most in English and Latin. The Tanzania education policy specifies that the medium language of instruction in primary must be Kiswahili, while English has to be used in post-primary education. Consequently, secondary school biology students find difficult to cope with learning in the context of foreign language. This paper aims at presenting the investigation on how pedagogical language strategies can effectively support teachers and learners during teaching and learning of systematic invertebrates in Tanzania secondary schools. Data were collected using the lesson observation checklist, lesson evaluation sheet, interview with teachers and focus group discussions with learners. A total of 60 sessions, each of 80 minutes were observed in 10 schools. A total of 40 teachers and 400 level four students of the ordinary level participated in the study. Quantitatively, paired sample t-test, means, standard deviations and percentages were used to evaluate and compare changes in learners' performance in preand post-tests. Further, thematic analysis was employed to analyse qualitative data. Key findings from the study indicated that the majority of teachers who participated in the training managed to set competencies and the activities to reinforce the achievements of developed competencies. Again, teachers and learners had a progressive significant improvement over introduced pedagogical language strategies. Overall, there was a statistically significant difference between pre- and post- intervention. Interviews with teachers and focus group discussions with students revealed that the strategies increased students' interactions and activeness in class, which in turn, improved the learning of biology content through the English language. This study therefore recommends the pedagogical language strategies to be adopted during teaching and learning of biology, specifically the content of invertebrate systematic.
\end{abstract}

Keywords: IBL, invertebrate systematic, language of instruction, pedagogical language strategies

\section{INTRODUCTION}

The teaching and learning of systematic of invertebrates require that both teacher and student communicate effectively (Ricketts, 2014). In Tanzania like in other countries worldwide, language plays a central role in education, specifically as a medium for teaching, learning, and assessment (Mozayan, 2015). The language plays a pivotal role in the development of subject-specific competencies as it enhances subject understanding, critical thinking, as well as information and ideas sharing (Semali \& Mehta, 2012). In this regard, language mediates the knowledge that is applied in problem solving (Barrett \& Bainton, 2016). Further, the primary function of language in instruction is to enable both teacher and learner to communicate and share knowledge with precision, as it has been indicated in

(c) 2021 by the authors; licensee Modestum. This article is an open access article distributed under the terms and conditions of the Creative Commons Attribution License (http://creativecommons.org/licenses/by/4.0/). 


\section{Contribution to the literature}

- This study indicates how pedagogical language strategies can effectively support teachers and learners during teaching and learning invertebrate systematic. Objectively evaluating effectiveness of pedagogical language strategies supported by inquiry-based learning (IBL) in teaching and learning invertebrate systematic in Tanzania secondary schools.

- Study outcomes inform policymakers and curriculum developers that a unified form of contentlanguage integrated learning strategies to effectively teach and learn biology subject is missing from the current Ministry of Education, Science, and Technology education policy.

- Results of the present research would also be useful to education stakeholders and biology teachers, who may wish to advance in content-language integrated learning.

another research conducted in Tanzania (Brock-Utne, 2014).

The teaching and learning process in Tanzania, notably at secondary school level, has been hampered by several challenges such as language of instruction, teaching methodology, and lack of teaching resources (Semali \& Mehta, 2012). The Tanzania education policy specifies that the medium language of instruction in primary must be Kiswahili, while English has to be used in post-primary education (Ministry of Education and Vocational Training [MoEVT], 2014a). However, learners in post-primary have struggled to learn effectively through English (Ndalichako \& Komba, 2014). Moreover, in schools where learners are not sufficiently proficient in the language of learning and teaching, the learning process is disconnected (Rubagumya, 2003). To overcome this challenge and make teaching and learning meaningful and interesting to students, teachers need to employ methods that promote learner centeredness with language support (Gabrieli, Sane, \& Alphonce, 2018).

Language in relation to teaching and learning of biology has been a challenge to Tanzania secondary education (Gabrieli, Sane, \& Alphonce, 2018). The reasons are not well documented, but studies conducted in Sub-Saharan Africa indicated that the language of instruction and the curricula heaviness become a challenge (Barrett \& Bainton, 2016; Brock-Utne, 2014). Further, most of the terms used to describe organisms under kingdom Animalia, specifically systematic of invertebrates, are in English and Latin (Hilippe et al., 2011). However, the English language is not used by students as well as teachers in everyday life (Rubagumya, 2003). In addition, more endeavor is required to understand the suitability of English as a language and method for scaffolding science learning, invertebrate systematic in this case (Gabrieli, Sane, \& Alphonce, 2018).

Dunn (2003) in his research, indicated that most of the learners are challenged by the content of invertebrates, particularly in classification. This becomes more complicated when teaching approaches used do not provide language support. The unsustainable solution adopted by some teachers in Tanzania is the use of a familiar language as a mean of supporting learners with English language difficulties. It is unsustainable due to the fact that from the policy level there is no clear address of content-language integrated learning. However, more than this is required as indicated by other studies (Barrett \& Bainton, 2016; Massler, Stotz, \& Queisser, 2014), which recommends language supportive pedagogy in science classrooms.

The effective teaching and learning of invertebrate systematic using English as a medium language of instruction requires appropriate pedagogy. Pedagogical language strategies (PLSs) in this case refers to a number of fundamental strategies which make up the fabric of classroom teaching and learning process meaningful. Different new learner-centered teaching and learning approaches have come into place as a means of addressing the content-language challenge (Barrett \& Bainton, 2016; Massler et al., 2014; Thaiposri \& Wannapiroon, 2015). More emphasis has been put on learner centered approaches such as inquiry-based learning (IBL). The IBL approach has been appreciated to involve data collection, allows prediction of the outcomes, helps to develop studying concepts, and making connections between new knowledge and previous skills. This is important in developing four English language skills specifically reading, writing, speaking and listening. Therefore, the IBL has somewhat been considered as potential pedagogy in supporting learners with language difficulties (Braden et al., 2016).

Unfortunately, the IBL practices are not common in Tanzanian schools. The study conducted by Mkimbili et al. (2017) indicated that teachers often do not practice the IBL in teaching and learning. The reason behind this behaviour is the lack of teaching and learning resources as it has been explained by Kinyota (2020). Despite the curriculum documents recommending teachers to use learner-centred pedagogy (MoEVT, 2014a), the use of teacher-centred pedagogy is still persistent in practice (Kinyota, Kavenuke, \& Mwakabenga, 2019). In relation with the language of instruction, the IBL demands active interactions between leaners and teachers and learning materials. These interactions depend on proper use of the language of instruction. However, this becomes a challenge for the majority of teachers in Tanzania as 
pointed out by Ndalichako and Komba (2014). Therefore, it appears that in Tanzania schools, the majority of students and teachers struggle with the language of instruction and instructional delivery.

Furthermore, pedagogical approaches such as content language integrated learning (CLIL) (1990s) and language supportive pedagogy (LSP) through language supportive teaching and textbook (LSTT) project were introduced in Tanzania. The CLIL and LSTT approaches emphasize on using familiar language, Kiswahili in particular, and subject activities to improve English (Barrett \& Bainton, 2016; Massler et al., 2014). However, LSTT extends to teachers' collaboration through lesson studies, activity-based lesson development and the development of language supportive STEM teaching materials (Barrett \& Bainton, 2016). Despite, the two approaches being used to respond to practice tensions created by the language in education policy, there is still a gap on how teaching and learning biology can effectively be done by using a more unified set of pedagogical language strategies through inquiry-based learning.

\section{Research Theoretical Context}

This study followed the social constructivism learning theory proposed by Levy Vygotsky in (1978). The theory reinforces culture and language through active learning. Research conducted by Burris and Garton (2007) indicated that learners taught using constructivism-based instructions show active engagement in the learning process and the understanding of the subject. In this theory, learning observes learners' context. In particular, social interactions, and conversation patterns (Davis, Sumara, \& Luce-Kepley, 2000). From this standpoint, learners build their understanding within small groups such as pairs for example. Again, subject content can further be understood if learners are given time to discuss and present the findings. In this case, for meaningful learning to occur, language of instruction needs to be understood for both teachers and students (Barrett, \& Bainton, 2016; Vygotsky, 1962).

We assumed that constructivism theory could enable us to understand the role of active learning with regard to learners' context such as culture and language (Vygotsky, 1962). We also assumed that learning of invertebrate systematic can be attained through the interaction and discovery of new ideas in the whole process of learning, where learners construct their knowledge (Amineh \& Asl, 2015; Rickets, 2014). This serve as a proof that the constructivism theory enables the development of cognitive language proficiency skills as it was indicated by another study conducted by Kimberly and Debora (2004) on approaches to biology teaching and learning. Again, considering the classroom itself as social environment, teachers have to provide support and bridge between different students' cultures, languages, and social values (Wells, 1999).

\section{Research Question}

This study seeks to fill the gap through answering the following research question: How effective pedagogical language strategies supported by inquiry-based learning (IBL) can be used in teaching and learning invertebrate systematic in Tanzania secondary schools? To answer this research question, we conducted research using biology subject, the content of invertebrate systematic. Biology subject possesses terms in two foreign languages namely Latin and English, thus justifies the choice. In addition, biology ranks among the least performed STEM subjects in national examinations of the ordinary level in past six years in Tanzania (MoEVT, 2014b; MoEST, 2015, 2016, 2017, 2018, 2019). The pedagogical language strategies focussed on are summarized in Table 1.

Table 1. Pedagogical language strategies (PLS) focussed on during the study

\begin{tabular}{lll}
\hline $\begin{array}{l}\text { Item number } \\
1\end{array}$ & $\begin{array}{l}\text { PLS } \\
\text { Use of language supportive activities } \\
\text { with examples from indigenous local } \\
\text { language }\end{array}$ & $\begin{array}{l}\text { Classroom practical application } \\
\text { Students' discussion during the group activity or experiment } \\
\text { using either English or another familiar language. The } \\
\text { presentation of findings from the group work or the } \\
\text { experiment was done in English. }\end{array}$ \\
\hline 2 & $\begin{array}{l}\text { Translate in the local language where } \\
\text { necessary }\end{array}$ & $\begin{array}{l}\text { Use of additional words from students' familiar language, } \\
\text { mainly Kiswahili to emphasize the subject-content concepts. }\end{array}$ \\
\hline $\begin{array}{l}\text { Interpret for learners when needed } \\
\text { dse of frequent probing questions with regard to students' } \\
\text { daily life experience }\end{array}$ \\
\hline 5 & $\begin{array}{l}\text { Guide students to read, write, and } \\
\text { pronounce correctly scientific names and } \\
\text { key terms in taxonomy }\end{array}$ & $\begin{array}{l}\text { Considering that subject-specific words had to be pronounced } \\
\text { correctly by students. }\end{array}$ \\
\hline 6 & $\begin{array}{l}\text { Use of language genres specific to the } \\
\text { subject and topics }\end{array}$ & $\begin{array}{l}\text { The use of technical words in every topic was considered as } \\
\text { vital to emphasise scientific literacy among students. }\end{array}$ \\
\hline 7 & $\begin{array}{l}\text { Provision of English words glossary for } \\
\text { subject terminologies }\end{array}$ & $\begin{array}{l}\text { This consisted of further explanations for key subject-specific } \\
\text { vocabulary. }\end{array}$ \\
\hline Use of simple English sentences & $\begin{array}{l}\text { The use of short English sentences to emphasize a certain } \\
\text { characteristic feature of invertebrates was considered. }\end{array}$ \\
\hline
\end{tabular}


Further, pedagogical language strategies indicated in Table 1 were categorized into six themes namely (1) lesson planning, (2) instructional strategies, (3) teaching and learning activities, (4) language guidance, (5) students' participation, and (6) inquiry process based on 5Es teaching and learning instructional model, where 5 Es stands for engage, explore, explain, elaborate and evaluate (Appendix 3).

\section{METHODOLOGY}

\section{Area of Study}

The United Republic of Tanzania is located in the East coast of Africa. Tanzania has Kiswahili and English as official languages (Galabawa, 2006). It has also more than 120 indigenous languages from more than 120 ethnic communities. Therefore, the country can be described as multilingual (Roy-Campbell, 1992). The English language is used as the language of instruction in secondary schools and post-secondary education (MoEVT, 2014a). This study was conducted in Dodoma region, the administrative capital of Tanzania with more than 200 secondary schools. The choice of Dodoma was justified by the fact that it ranked among the regions which had poor performance in biology subject in form four National examinations in past 6 years (MoEVT, 2014b, MoEST, 2015, 2016, 2017; 2018, 2019). One of the courses of this poor performance was ascertained to be the lack of teaching and learning resources and language of instruction (Gabrieli, Sane, \& Alphonce, 2018).

In this region, data were collected in 10 schools purposively selected based on availability of teaching and learning resources. Further, the criteria for school's selection were based on ranks in biology subject performance in the ordinary level national examination during past six years. In this regard, 4 schools ranked as low, 3 schools ranked as medium and 3 schools ranked as high were selected. In addition, the sufficient number of biology teachers as well as students' ratio were considered, targeting form four of secondary level education (MoEVT, 2010).

\section{Research Approach and Design}

This study involved mixed-method research approach. The qualitative approach was used to explore biology teachers' and students' feelings about methodology in teaching and learning of systematic invertebrates with language support. This was aided by interviews with biology teachers and focus group discussions with students. Moreover, the ex-post facto quantitative approach (Creswell, 2012) including preand post-lesson formative assessment was employed to ascertain the differences in student's adaptations over pedagogical language strategies introduced in learning invertebrates' content (Jacoby et al., 2013). The motivation to use the formative assessment is rooted in the findings of a study conducted by Kwan (2011) which points that formative assessment is appreciated to disclose feedbacks to identify and distinguish differences in students' knowledge within the subject. Therefore, students received feedback from the teacher during and after the lesson from different activities performed. Further, formative assessment was used to evaluate the effectiveness of pedagogical language strategies in teaching and learning of biology, content of systematic invertebrate.

In Tanzania, the content of invertebrates is concerned with the Phyla of Platyhelminthes, Aschelminthes (Nematoda), Annelida, and Arthropoda. This content was distributed in 6 lessons at school level as follows: (1) general and distinctive features of the kingdom Animalia, (2) major phyla of kingdom Animalia, (3) features, economic importance, and systematic of the phylum Platyhelminthes, (4) features, economic importance, and systematic of the phylum Aschelminths, (5) features, economic importance, and systematic of the phylum Annelida, and (6) features, economic importance, and systematic of the phylum Arthropoda.

During this study, the lesson 2 to 6 were observed and improved (MoEVT, 2010), based on researchers' assumption that the lesson one served as the baseline to other lessons. On the other hand, the choice of invertebrate systematic is justified by the potential ecological role of invertebrates such as parasitism, herbivory, predation, mutualism, and competition (Kellert, 1993). Furthermore, the content was selected based on the challenges faced by both teachers and learners in terms of the scientific names that are in Latin, and the fact that most of these animals are not available in school locations. These are added to the teaching and learning of systematic of invertebrates dominated by teacher-centred pedagogy with less emphasis on handson activities (Kinyota, Kavenuke, \& Mwakabenga, 2019), hence taught theoretically.

To assess the effects of PLS, lessons based on the content of invertebrate, specifically the Phylum Platyhelminthes, Arthropoda, and Annelida. The organisms were studied considering their economic importance for the human being. The IBL approach as a teaching methodology that embraces collaborative and active learning of an individual student (Bybee, 2002) was applied. Activities were divided based on each IBL level and phase. For example, during engage/excite, students were required to observe physical appearance of organisms such as the shape of the body, presence and absence of antenna, presence of compounds eyes, wings. Based on observed features students were helped by teachers to formulate the key question, which was explored by performing prepared activities in explore phase. Further, in explain phase students had to present their findings from the activity done, while in elaborate phase, the teacher gave an additional activity to apply 
learnt subject content in the leaners' everyday life. Finally, the teacher had to evaluate students' lesson understanding by providing evaluation questions. Reading, listening, writing, and speaking skills were analysed across all phases of the lesson.

\section{Sample Characteristics}

A total of 40 teachers participated in the study (20 biology and 20 language teachers), and 400 form four students (40 from each school). Teacher participants involved in the teaching of the content had achieved either a bachelor degree in the field of science education from a national or international recognized university. All teachers had teaching experience of more than 4 years. Besides, students in this study were all from year four of ordinary secondary education with regular attendance at school. The characteristics mentioned may serve as evidence to validate the pedagogical classroom observation practice.

\section{Data Collection}

Data were collected for a period of 15 weeks in between June and October, 2020. Stage 1 was carried out within 5 weeks in June and July 2020 while stages 2, 3, and 4 lasted for weeks starting from the end of July to September 2020. A total of 60 sessions, each of 80 minutes were observed in 10 schools. At school level, six classroom sessions were carried out, equivalent to six cycles. We considered at least 6 lessons at school level to clearly ascertain the intervention variations from the baseline. A total of 40 teachers (Biology: 20 - two from each school, Language: 20 - two from each school) and 400 students (40 from each school) from level four of the ordinary level participated in the study. Language in education specialists and/or teachers were engaged with identification and correction of English grammatical errors and pronunciations while providing their expertise in teaching methodology. Both language and biology teachers and researchers attended the lessons as observers. Besides, biology teachers were engaged in both teaching the subject content and support learners with language. Sample size of students was chosen based on the recommended class size in Tanzania which should not exceed 40 students (MoEST, 2019), while that of teachers depended on the number of biology and language teachers available at school level. Gender was considered in each stage whereby 240 (60.0 $\%)$ male and $160(40.0 \%)$ female students participated in this study. Besides, out of 40 teachers 15 (37.5\%) were females.

Before each stage a consent form was signed and/or obtained from participants and the purpose of research was explicitly explained. Moreover, when a student was less than 16 years old, ethical clearance was issued from parents. Nevertheless, participants were assured that the information and data would only be used for educational purposes and their identity/names should not be publicly revealed in any case. A total of 60 lessons (six consecutive lesson observations from each school) were carried out following four stages, namely: Pre-test and lesson observation, Lesson improvement, Lesson implementation and lesson observation, and Post-lesson evaluation.

\section{Stage 1: Pre-test and lesson observation}

This stage involved lesson observation and formative assessment before the introduction of PLS. A total of 20 teachers (two from each school) purposively selected were interviewed to ascertain their views about supporting learners with English language difficulties in learning the content of systematic of invertebrates. Formatively, students were tested using pre-prepared questions in relation with the lesson covered (Appendix 4). The main focus was on students language support, quality of scientific literacy, and the correctness of students answers from the given questions. Data were collected using observation checklist (Appendix 1), interviews, marking of the evaluation sheets and marks recording. The feedback from stage 1 was used to formulate the intervention to help teachers and learners to overcome identified pedagogical challenges.

\section{Stage 2: Lesson improvement}

After stage one, a training on various pedagogical language strategies was organized to all teachers at school level. This was followed by experience sharing about the inquiry process and pedagogical language strategies. Then after, the 80 minutes biology lesson observed in stage 1 was improved. The improvement consisted of the subject content and learning resources. In the improved lesson, the elements of language objectives were introduced as a new entity indicating lesson activities. The prepared activities would then support learners with language for a meaningful understanding of the lesson content. In addition, the class exercise was prepared by the aid of table of specification.

The following were the language pedagogical strategies of our great focus in the revised lesson: use of language supportive activities to explain the abstract concepts of the subject content guided by inquiry process, translate when necessary (bilingual instructions), interpret for students, help students to pronounce correctly, use of language genres specific to the subject and topics, provision of a glossary, and use of simple English sentences. Further, researcher team recorded data on changes in the revised biology lesson plans and information obtained from experience sharing using notebooks. 


\section{Stage 3: Lesson implementation and lesson observation}

This stage involved teaching the lesson prepared in stage 1 and improved in stage 2. Biology teachers involved in teaching the lesson agreed that one of them would volunteer to teach while the rest remain as observers. Students were given equal opportunity to learn and collaborate during the lesson. In group discussions students were allowed to discuss in a familiar language, Kiswahili in this case, and report their answers in English. Observers used a pre-prepared observational checklist with a total of 28 items to assess the effectiveness of pedagogical language strategies indicated in the lesson plan. Teachers' interactions with students throughout the lesson and challenges faced were noted down. Moreover, the ability of learners in speaking and reading skills were recorded for further evaluation.

\section{Stage 4: Post-lesson evaluation}

This stage entailed evaluating the success and points of improvement from the lesson. It focused on both teacher and students' participation. The researcher team and teachers reflected on how the pedagogical language strategies supported the teaching process discussed and the points that need improvement. At this point each observer provided the feedback based on the checklist. To capture differences experienced by students the interviews were organized with 120 students. Further, the separate focus group discussions of 15 to 20minutes time each were organized with 10 students at school level. Data on advantages of teaching using the pedagogical language strategies were also collected through the interview with 20 biology teachers who taught the lesson.

At the end of the lesson, all students who attended the revised lesson were assessed. The learners' evaluation was composed of mixed questions from multiple choices, and open-ended questions. The questions were pre-prepared by the teacher following the Bloom's taxonomy (Yang, 2017). Scripts were collected and marked, and the passing mark was set at $50.0 \%$. To control biases during marking, each member of the team checked each script. An independent verifier was chosen out of the researcher team to check and mark the scripts for confirmation. The person selected had skills in measurement and evaluation in education. Results were then recorded and compared with those of the pre-test and lesson observation to evaluate changes in performance. Finally, each individual student's English writing, reading, speaking and listening skills were checked over the set of given writing and reading class session activity.

\section{Validity and Reliability of Data Collection Instruments}

\section{Observational checklist}

Given that we aimed at presenting the investigations on the present pedagogical language strategies used by teachers to support learners with language difficulties in learning about invertebrate systematic, we decided to develop an observational checklist that could be used to capture the teacher and student's active learning. Our observational checklist documented several aspects of pedagogical language strategies used in biology classroom: (1) Lesson plan (2) Instructional strategies (3) Teaching and learning activities (4) Language guidance (5) Students' participation in the lesson (6) Inquiry process. The six aspects bring a total of 28 items observed and rated. Since observers' agreement may occur by chance, we decided to conduct inter-observer's agreement reliability test, the Cohen's Kappa coefficient (Cohen, 1988) using SPSS 16.0. The Kappa calculation was based on researcher (R) observation and research assistants' (RA, RA1 and RA2) observation.

Kappa coefficient was calculated using the following formula: $\mathrm{ka}=(\operatorname{Pr}(\mathrm{a})-\operatorname{Pr}(\mathrm{e})(1-\operatorname{Pr}(\mathrm{e})$. Where: $\operatorname{Pr}(\mathrm{a})=$ Relative observed agreement or rate of agreement between observers, $\operatorname{Pr}(\mathrm{e})=$ The probability of agreement based on chance or the rate of inter-observer agreement products between observers (what was observed by $\mathrm{R}$ only and RA only), $\mathrm{k}=$ Cohen's Kappa coefficient, $\operatorname{Pr}(\mathrm{a})=$ agreement of unsatisfactory + Agreement of satisfactory/Total agreement of satisfactory and unsatisfactory, $\operatorname{Pr}(\mathrm{e})=(\%$ total of unsatisfactory $(\mathrm{RA}) \mathrm{x}$ $\%$ total of unsatisfactory (Researcher) $+(\%$ total of satisfactory (RA) $+\%$ total of satisfactory (Researcher). In this regard, the number $1=$ satisfactory and $2=$ unsatisfactory. The value of Kappa coefficient $(\mathrm{ka})$ was found to be $0.77,0.78$, and 0.80 across three observer pairs. Cohen (1988) indicates that the Kappa values varying from 0 to 1 indicate agreement due to chance between observers, 0.7 being considered as minimum acceptable level while 0.75 and above are considered as excellent agreement.

\section{Evaluation sheet, focus group discussions and interviews}

Furthermore, evaluation sheets, interviews and focus group discussions were used to confirm the validity of observational checklist used (Maxwell, 2012). After pilot study, three observers observed the same class, wrote down their observations, and discussed answers as a group identifying the points of agreement and improvement (Mitchell, 1979). Further, content validity was ensured by submitting the evaluation sheet, interview schedule, observational checklist and focus group discussion topic for a review by experts from biology, language/linguistic, and education. In 
addition, teachers were involved in the development of an observational checklist.

Nevertheless, The Cronbach's coefficient alpha was calculated for a five-point rating scale evaluation sheet involving reading and writing tested students' English language skills basing on the following formula: $a=\mathrm{k} / \mathrm{k}$ $1\left(1-\sum_{\mathrm{i}} \mathrm{k}_{1 \mathrm{k}} \sigma_{\mathrm{i}}{ }^{2} / \sigma_{\mathrm{t}}{ }^{2}\right)$ whereby: ${ }_{k}$ is the number of items in a scale, $\sigma_{\mathrm{i}}^{2}$ is the variance of $i^{\text {th }}$ item and $\sigma_{\mathrm{t}}^{2}$ is the variance of total scores (Cronbach, \& Shavelson, 2004). The $a$ calculation was done in SPSS 16.0, to provide an indication of the average correlation among all of the items that make up the scale (Creswell, 2012). The Cronbach's coefficient alpha was found to be 0.8 , with $\mathrm{N}$ $=40(\mathrm{~N}$ is the total number of participants $)$. The Cronbach's values must be ranging from 0 to 1 , with 1 indicating greater reliability (Creswell, 2012). In this study, the Cronbach's coefficient alpha was 0.8 and this implies an acceptable internal consistency between the items.

\section{Control of threats to internal validity}

Maxwell (2012) provides several recommendations for studies involving observations such as investing adequate time in the field with the participants over the same topic. In this case, we planned for several class sessions in a total of five to six cycles for a period of 15 weeks. The reason behind was to enable participants and observers performance remain natural. Again, the content revolved around systematic invertebrates only, which was divided into six-subtopics based on the current Tanzania Biology syllabus (MoEVT, 2010). Multiple sources of data including students' evaluation sheets, focus group discussions, and interviews with students and teachers were used to ensure that data do not apply to only one observation and/or one sample population. Moreover, evaluation questions were set based on Bloom's taxonomy.

\section{Data Analysis}

At every stage, data collected were coded and transcribed. Quantitatively, paired sample t-test, means, standard deviations were used to compare changes in teachers and learners' performance in pre- and posttests. This was based on the performance in the content questions before and after intervention. Further, means and standard deviations were used to test for the extent to which the pedagogical language strategies impacted on teaching and learning of invertebrate systematic. Percentages were specifically used to evaluate biology teachers' and learners' status before and after the introduction of pedagogical language strategies. In addition, the percentages were calculated based on the single score over the total range scores.

Further, data from observational checklist and the mean scores were computed on a 0-4-point scale ranging from 0: not evident/occurred to 4: frequently evident.
The observational checklist had a total of 28 items, categorized into six themes: (1) Lesson planning (items $1,2,3$ ), instructional strategies (items 4, 5, 6, 7, 8, 9), teaching and learning activities (items 10, 11, 12, 13), language guidance (items 14, 15, 16, 17, 18, 19), students' participation (items 20, 21, 22, 23, 24), and inquiry process (items 25, 26, 27, 28). Each of these items contributed independently and from ranks for each item, the mean and standard deviation were calculated. Further, significance differences at 95\% confidence interval ( $P$ values) were calculated and indicated by the letters. The analysis was done using SPSS 16 software.

Besides, during qualitative analysis, themes being generated from data were established and thematically analysed. This involved data from interviews with teachers and focus group discussions with students. SPSS 16.0 software and Microsoft Excel 2016 were used. Further, the writing, reading and speaking skills consisting of categorical variables related to learners' performance were set to standards as per five-point rating scale adapted from Shohamy, Gordon, \& Kraemer (1992) and Knoch (2011).

\section{RESULTS}

\section{Stage 1: Pre-test and Lesson Observation}

Results collected from pre-test under the lesson plan theme, indicated that none of teachers was able to set language objectives to be achieved in class $(0 \pm 0.00, \mathrm{P}$ $<0.05)$. Similarly, under instructional strategies teachers totally failed to provide the ways that are able to encourage learners to answer in English through questioning. On the same theme teachers also failed to demonstrate ability to link the present subject with the previous learning in a proper and clear English adapted to the level of learners. The captured interview with teacher from school 1 can serve as evidence:

\section{"Teaching biology particularly classification of animals using English language only is a challenge to me. I wish we can be introduced to some language strategies which would help us during teaching".}

Some teachers exhibited the use of inappropriate technical verbs or phrases for example "many invertebrates are small organisms" instead of "majority of invertebrates are microscopic organisms". Besides, the focus group discussion with students revealed that majority of students struggle with the use of English during teaching and learning as one of captured evidence below reveals:

We are having trouble communicating in English as at home we are speaking Kiswahili. Again, when we go to class in Biology session what seems to be important is to cram what the teacher teaches so that we may pass our exams well (student from school 10). 
Table 2. Overall analysis of six themes $(\mathrm{a}=\mathrm{p}$-value $\mathrm{P}<0.05)$

\begin{tabular}{lcccc}
\hline No & $\begin{array}{c}\text { Pedagogical language strategy } \\
\text { theme }\end{array}$ & $\begin{array}{c}\text { Items in Appendix 1 } \\
\text { and Appendix 2 }\end{array}$ & $\begin{array}{c}\text { Pre-intervention (Mean } \pm \\
\text { SD and P value) }\end{array}$ & $\begin{array}{c}\text { Post -intervention (Mean } \\
\pm \text { SD and P value) }\end{array}$ \\
\hline 1 & Lesson planning & $1,2,3$ & $2.3 \pm 0.0^{\mathrm{a}}$ & $3.4 \pm 0.8^{\mathrm{a}}$ \\
2 & Instructional strategies & $4,5,6,7,8,9$ & $0.6 \pm 0.1^{\mathrm{a}}$ & $2.5 \pm 0.8^{\mathrm{a}}$ \\
3 & Teaching and learning activities & $10,11,12,13$ & $0.5 \pm 0.3^{\mathrm{a}}$ & $2.5 \pm 1.0^{\mathrm{a}}$ \\
4 & Language guidance & $14,15,16,17,18,19$ & $0.6 \pm 0.4^{\mathrm{a}}$ & $2.1 \pm 0.7^{\mathrm{a}}$ \\
5 & Students' participation in the lesson & $20,21,22,23,24$ & $1.5 \pm 0.1^{\mathrm{a}}$ & $2.6 \pm 0.9^{\mathrm{a}}$ \\
6 & Inquiry process & $25,26,27,28$ & $1.0 \pm 0.0^{\mathrm{a}}$ & $2.8 \pm 1.0^{\mathrm{a}}$ \\
\hline \multicolumn{7}{r}{ Overall scores } & $0.9 \pm 0.2^{\mathrm{a}}$ & $2.5 \pm 0.9^{\mathrm{a}}$
\end{tabular}

In contrary, a substantial number (item $1,4 \pm 0.00, \mathrm{P}$ $<0.05$ ) of teachers were able to set competencies to achieve in class (Appendix 1). Further, some characteristics of leaner centred approach were observed such as allowing students to sit in groups to work on given activities (item 17.3 $\pm 1.00, \mathrm{P}<0.05$ ). The evaluation ( $\mathrm{N}=400$ students) of the use of English language during the teaching and learning invertebrates showed poor reading skills. Results indicated that $40.0 \%$ of students had poor ranking, others $51.0 \%$ had very poor ranking, and the ranking of other $9.0 \%$ indicated that they did not have any accuracy in reading the content.

No student had accurate and fairly accurate ranking during the evaluation of the English language writing skills. Further, few students $(20.0 \%)$ could be ranked as having a fairly accurate. This means that the reading was adhering to correct pronunciation, but it did not respect pauses and there was not any fluency. Poor reading skills was found for other $30.0 \%$ and it was for those students who had the reading which did not adhere to pauses, correct pronunciation, and fluency. Other $30.0 \%$ had the reading which was completely not adhering to correct pronunciation, pauses, and fluency. Moreover, around $10.0 \%$ completely failed to read the sentence. $35.0 \%$ of learners passed the content exercise with marks scored $50.0 \%$ or above. However, Majority of students $(65.0 \%)$ failed the exercise having the marks below $50.0 \%$.

\section{Stage 2: Lesson Improvement}

Results of this stage $(\mathrm{N}=20)$ indicated that the majority of teachers who participated in the training managed to set competencies $(95.0 \%)$, and the activities to reinforce the achievement of developed competencies. However, only $85.0 \%$ of these teachers could set the language objectives to be achieved in class, during teaching and learning of invertebrate systematic. Evidence from interview and experience sharing revealed that the introduction of pedagogical language strategies was helpful to teachers. For example, a teacher from school 8 said:

"I appreciate and agree on the role of language as at the end students will need to write and critically think using language in the context of learning biology".

\section{Stage 3: Lesson implementation}

It was observed (Appendix 2) that there was a progressive improvement in lesson planning. Further, the improvement was indicated by the performance of participants over the given pedagogical language strategies. Results indicated also statistical significance differences between means, which again confirms that both learner and teacher performance was changing during the course of time. Finally, teachers were able to set competencies to achieve in class in all five cycles at the same pace, and at some point teachers and learners were adapting to PLSs introduced from one cycle to another.

\section{Stage 4: Post-lesson Evaluation}

Table 2 displays an overall analysis of six themes in pre- and post-intervention computed on a 0 - 4-point scale. The analysis confirms the progressive improvement in the lesson development as it can be observed from overall scores row.

Further, a sample paired t-test was carried out to ascertain if there was a statistically significant difference between pre- and post- intervention. The t-test was set at 95\% Confidence Interval of the Difference. The results were as follows: Mean $=0.9, \mathrm{SD}=0.5$ to Mean $=2.6, \mathrm{SD}$ $0.9), \mathrm{t}_{(4)}=8.1, \mathrm{P}<0.05$, Lower $=1.0$, Upper $=2.0$. The results indicated that there was a statistically significant differences between the pre- and post-intervention. The reasons behind this improvement can be explained in the context of the introduction of the PLS. It appeared that teachers had limited ways of supporting learners with language before intervention. In some occasions, interviews with teachers revealed that this role was ignored by the majority of biology teachers. In essence, the statistical difference confirms that the introduced pedagogical language strategies in aggregate had helped teachers to improve in teaching and learners' academic performance over subject-content.

Finally, marks from the individual student's English writing, reading, speaking and listening skills assessment over the set of given writing and reading class session activity indicated that all students scored at $50.0 \%$ and above compared to before the intervention, where $62.5 \%$ of students could not attain $50.0 \%$. 


\section{DISCUSSION}

\section{Biology Language Supportive Lesson Planning}

Results collected from pre-test revealed that biology teachers could not manage to set language objectives to be achieved in class. The reason behind can well be explained by lack of such important element in the current Tanzania biology syllabus (MoEVT, 2010), teachers' expertise and teaching and learning resources (Gabrieli, Sane, \& Alphonce, 2018). In teachers' expertise aspect, the challenge was on the identification of content and language specific objectives. Barrett and Bainton (2016) argues that each subject discipline represents a 'community of practice' with its own set of formalised language practices. In other words, technical language is characterized by subject-specific vocabulary. For example, Biology of invertebrates, in particular, uses the specific language with words such as Triploblastic, Acoelomate, Arachnida, and Myriapoda. Therefore, during lesson planning biology teachers need to consider setting the language instructional objectives to be achieved in class through identification of subjectspecific vocabulary.

Moreover, it appeared that a substantial number of teachers were able to set competencies to achieve in class. The reason behind could be explained by the demands of the current biology syllabus, the syllabus clearly shows step-by-step a teacher can follow to prepare the lesson. In addition, intensive lesson preparations by researcher team helped teachers to mainly start improving, particularly on how to set language objectives, teachers were able to prepare improved lesson plans (Appendix 5). In the former lesson plan the language objective aspect was not considered. Rubagumya (2003) argues that learners need to be supported to develop a small number of specific language skills. Barrett and Bainton (2016) extend that language academic skills can be achieved through a set of well-planned activities. In this case, in lesson improvement, the selection of teaching and learning activities were set to develop both language skills and content mastery. For example, the use of potential English texts, oral presentations, and essay writing from the set of a given exercise. In short, lesson planning appears to be the core of any teaching and learning support initiative.

\section{Instructional Strategies in Teaching and Learning Invertebrate Systematic}

At the pre-test, this study found that teachers totally failed to provide the ways that are able to encourage learners to answer in English through questioning. This is added to failure in demonstrating the ability to link the present subject with the previous learning in a proper and clear English adapted to the level of learners. Lack of expertise on how to link the curricular content and language appeared to be the reason. Vygotsky (1962) argues that language mediates learners thought process through social interactions hence a cognitive tool. Further, some biology teachers unknowingly believed that it is none of their responsibility to take trouble for learners' academic language proficiency development. Moreover, considering the preparation of learners to be strategic and independent leaners, in lesson implementation and observation, we emphasized much on the learner centred instructional strategies (Orlich, Harder, \& Callahan, 2007). The teacher facilitation for questions, presentations and student discussions provided positive results. In essences, it is important for teachers to develop some skills of integrating the content and language.

\section{Teaching and Learning Activities Fostering Subject Content Mastery and Academic Language Proficiency}

In pre-test, teachers had a good knowledge of what it means by leaner-centred activities, but not with language support. However, progressive improvement was noticed during and after the intervention as it can be observed in Appendix 6. This evidence shows how mistakes committed in writing were progressively minimized by students such as misspelled words. In lesson implementation and observation, Teaching and learning activities were explicitly underpinned by social constructivism theory. For example, the use of biology practical group work activities, attention to dialogue and individual student test. Schweisfurth (2013) argues that group work might be considered as indicative of interactive learning while dialogue may indicate that learner spoken and written texts are limited.

To counter this argument, leaners were placed in smaller groups of four to five individuals and where it was necessary only in pairs and allowed to present their findings after every group task. Again, the formative assessment was done as a means to bring the feedback in the process, class session activities were well performed by students after introducing the pedagogical language strategies. Activities were further linked to daily life applications. Barrett and Bainton (2016) points out that relating formal and informal knowledge is a common characteristic of secondary school learning, where students are expected to relate principles and classifications to observations of their own environment. Generally, the use of language supportive activities enhances learning of the subject knowledge and development of language skills.

\section{Subject Language Guidance During Teaching and Learning Invertebrate Systematic}

In pre-test teachers totally failed to facilitate the use of simple English sentences to enable students share the thoughts with each other in English. The reason can be explained by considering pedagogical role of a teacher. 
From constructivists view, (Vygotsky, 1978), the teacher is a facilitator of learning process. Further the knowledge is not assumed to be owned by a teacher. This establishes a social environment, classroom, which a teacher needs to bridge it with the subject knowledge through language (Wells, 1999). In our study, the teacher had the following subject language guidance roles: correct student-oriented feedback using clear English, help students to clarify ideas in English, guide students to use appropriate terminology, asks students to make group discussions discussing in a familiar language (Kiswahili in this case) and report back to class in simple English sentences, and allow students share the thoughts with each other in English. In aggregate, teachers improved in guiding the learners using English. Barrett and Bainton (2016) asserts that strengthening classrooms to become places where student talk is genuinely exploratory and collaborative. In essence, in collaborative with language in education specialists biology teacher can potentially develop skills to support learners with language.

\section{Inquiry Process and Students' Participation in Invertebrate Systematic Lesson}

The principle of inquiry was put in place to develop learners' critical thinking skills (Thaiposri \& Wannapiroon, 2015) following the engagement, exploration, explanation, elaboration and evaluation phases of the inquiry-based learning. The learning inquiry cycle model, based on Piaget's theory of cognitive learning (Bevevino, Dengel, \& Adams, 1999). In this regard, biology practical activities involving live and preserved specimens were carried out. Under inquiry process, it was observed that learners were able to appeal for higher orders of thinking and remain active during the teaching and learning process. All three important types of classroom interactions: teacherlearner, learner-leaner, learner-material, were ensured. Besides, Moate (2010) argues that in social-cultural learning context language initiates the contextualization of knowledge to learners. This implies that principles of inquiry unlock the potentials for the language used so that a learner can easily comprehend the information.

Furthermore, the inclusion of the bilingual learning in the principles of inquiry advanced the performance of particular learners' activities. Interesting observation was that students were able to remember the invertebrate specimens in their local names. This reveals how bilingual instructions can support learners to comprehend the information aided by inquiry-based learning. Again, under bilingual instructions, the investigation by this study advocates that consideration of students' familiar language has the potential to convert interrelationships between teachers and students, and students themselves. Swain (2000) points that comprehensibility is achieved as conversers repeat and rephrase from conversational partners. The significance of learning within a bilingual context is that it helps learners connect the knowledge to their real-life environment. In addition, Barrett and Bainton (2016) note that it draws students' attention. In essence, through inquiry based learning the discussion of meaning of invertebrate systematic concepts became central.

The questions conjured by this study is to know how and when the mentioned strategies can be used in classroom, specifically, in the teaching and learning biology with a good choice of language supportive teaching and learning resources such as text-books? We appeal to teachers to take charge and consider that for a meaningful learning to occur subject content and language of instruction should not be considered as separate pedagogical entities.

\section{CONCLUSION AND RECOMMENDATIONS}

Generally, it was evident that after exposure to a set of pedagogical language strategies both teachers and students improved on the way of teaching and answering the content questions, respectively. It suffices to recommend for practice: for students to learn Biology, specifically content of systematic invertebrates, meaningfully, the teaching and learning need to recognize language pedagogical strategies which encompass: use of language supportive activities, translate when necessary, interpret for students, help students to pronounce correctly, use of language genres specific to the subject and the topics, provision of a glossary, and use of simple English sentences. Again, professional development can increase classroom writing and reading activities through training and workshops as biology teachers can critically develop their ability in teaching with language support. For policy: the use of bilingual instructions can be considered for inclusion in the current Tanzania language in education policy.

\section{ACKNOWLEDGEMENTS}

We owe a debt of gratitude to the Management of African Centre of Excellence for Innovative Teaching and Learning Mathematics and Science (ACEITLMS) based at the University of Rwanda, College of Education for funding this research project. We also cordially thank The United Republic of Tanzania, President's Office Regional Administration and Local Government for research permit. Finally, we are grateful to the participants for the breadth of information they shared with us.

\section{REFERENCES}

Amineh, R. J., \& Asl, H. D. (2015). Review of Constructivism and Social Constructivism. Journal of Social Sciences, Literature, and Languages, 1(1), 9-16. 
Barrett, M. A., \& Bainton, D. (2016). Re-interpreting relevant learning: an evaluative framework for secondary education in a global language. Comparative Education, 52(3), 392-407. https: / / doi.org/10.1080/03050068.2016.1185271

Bevevino, M., Dengel, J., \& Adams, K. (1999). Constructivist theory in the classroom. Internalizing concepts through inquiry learning. The Clearing House: A Journal of Educational Strategies, Issues, and Ideas, 72(10), 275-278, https:/ / doi.org/10.1080/00098659909599406

Braden, S., Wassell, B. A., Scantlebury, K., \& Grover, A. (2016): Supporting language learners in science classrooms: insights from middle-school English language learner students. Language and Education, 30(5), 438-458. https:// doi.org/10.1080/09500782. 2015.1134566

Brock-Utne, B. (2014). Language-in-Education Policies and Practices in Africa with a Special Focus on Tanzania and South Africa. In J. Zadja (Ed.), Second International Handbook on Globalisation, Education and Policy Research (pp. 615-631). Dordrecht: Springer. https://doi.org/10.1007/978-94-0179493-0_36

Burris, S., \& Garton, B. L. (2007). Effect of instructional strategy on critical thinking and content knowledge: Using problem based learning in the secondary classroom. Journal of Agricultural Education, 48(1), 106-115. https:/ / doi.org/10.5032/ jae.2007.01106

Bybee, R. W. (2002). Scientific inquiry, student learning, and the science curriculum: Learning science and the science of learning. Arlington, VA: NSTA Press. https:/ / doi.org/10.2505/9780873552080

Cohen, J. (1988). Statistical Power Analysis for the Behavioral Sciences (2nd Ed.). Lawrence Erlbaum Associates, Publishers.

Creswell, J. W. (2012). Educational research: Planning, conducting and evaluating quantitative and qualitative research $\left(4^{\text {th }}\right.$ Ed.). Upper Saddle River: Pearson Merrill Prentice Hall.

Cronbach, L. J., \& Shavelson, R. J. (2004). My current thoughts on coefficient alpha and successor procedures. Educational and Psychological Measurement, 64(3), 391-418. https://doi.org/ $10.1177 / 0013164404266386$

Davis, B., Sumara, D., \& Luce-Kepley, R. (2000). Engaging Minds-Learning and Teaching in a Complex World. London: Lawrence Erlbaum Associates Publishers.

Dunn, C. P. (2003). Keeping taxonomy based in morphology. Trends in Ecology and Evolution, 18, 270-271. https://doi.org/10.1016/S0169-5347(03) 00094-6

Gabrieli, P., Sane, E., \& Alphonce, R. (2018). From Access to Quality Secondary Education: Developing Language Supportive Textbooks to Enhance
Teaching and Learning of Biology Subject in Tanzania, Journal of Education, Society and Behavioural Science, 25(1), 1-15. https://doi.org/ 10.9734/JESBS/2018/40999

Galabawa, J. C. J. (2006). Implications of Changing the Language of Instructions in Secondary and Tertiary Education in Tanzania. In B. Brock-Utne, Z. Desai, \& M. Qorro (Eds.). Focus on Fresh Data on the Language of Instruction Debate in Tanzania and South Africa. Dar es Salaam: African Minds. https://doi.org/10.1163/9789460912221011

Hilippe, H., Brinkmann, H., Copley, R. R., Moroz, L. L., Nakano, H., Poustka, A. J., ... Telford, M. J. (2011). Acoelomorph flatworms are deuterostomes related to Xenoturbella. Nature, 470, 255-258. https:/ / doi.org/10.1038/nature09676

Jacoby, C., Heugh, J., Bax, S., \& Branford-White, C. (2013). Enhancing learning through formative assessment. Innovations in Education and Teaching International, 51(1), 72-83. https:/ / doi.org/10.1080/ 14703297.2013.771970

Kellert, S. R. (1993). Values and Perceptions of Invertebrates. Conservation Biology, 7(4), 845-855. https:/ / doi:10.1046/j.1523-1739.1993.740845.x

Kimberly, T., \& Debora, A. (2004). Approaches to Biology Teaching and Learning: Learning Styles and the Problem of Instructional SelectionEngaging All students in Science courses. Cell biology education, winter, 3(4), 197-201. https://doi.org/10.1187/cbe.04- 07-0050

Kinyota, M. (2020). The status of and challenges facing secondary science teaching in Tanzania: a focus on inquiry-based science teaching and the nature of science. International Journal of Science Education, 42(13), 2126-2144. https://doi.org/10.1080/ 09500693.2020 .1813348

Kinyota, M., Kavenuke, P. S., \& Mwakabenga, R. J. (2019). Promoting teacher professional learning in Tanzanian schools: Lessons from Chinese schoolbased professional learning communities. Journal of Education, Humanities and Sciences, 8(1), 47-63.

Knoch, U. (2011). Rating scales for diagnostic assessment of writing: What should they look like and where should the criteria come from? Assessing Writing, 16(1), 81-96. https://doi.org/10.1016/j.asw.2011. 02.03

Kwan, F. (2011). Formative assessment: The one-minute paper vs. the daily quiz. Journal of Instructional Pedagogies, 5, 1-8.

Lewis, B., Sarah, S., \& Freedman, W. (2010). Language policy, multilingual education, and power in Rwanda. Language policy, 9, 191-215. https:/ / doi.org/10.1007/s10993-010-9170-7

Massler, U., Stotz, D., \& Queisser, C. (2014). Assessment instruments for primary CLIL: The conceptualisation and evaluation of test tasks. The 
Language Learning Journal, 42, 137-150. https:// doi.org/10.1080/09571736.2014.891371

Maxwell, J. A. (2012). Qualitative research design: An interactive approach (Vol. 41). Sage.

Mkimbili, S. T., Tiplic, D., \& Ødegaard, M. (2017). The role played by contextual challenges In practising inquiry-based science teaching in Tanzania secondary schools. African Journal of Research in Mathematics, Science and Technology Education, 21(2), 211-221.

https:// doi.org/10.1080/18117295.2017.1333752

Mitchell, S. K. (1979). Interobserver agreement, reliability, and generalizability of data collected in observational studies. Psychological Bulletin, 86(2), 376-390. https:// doi.org/10.1037/0033-2909.86.2. 376

Moate, J. (2010). The Integrated Nature of CLIL: A Sociocultural Perspective. International CLIL Research Journal, 1(3), 38-45. Retrieved from http:/ / www.icrj.eu/13/article4.html

MoEST. (2015). Basic Education Statistics of Tanzania (BEST). Dar es Salaam: Ministry of Education, Science, and Technology.

MoEST. (2016). Basic Education Statistics of Tanzania (BEST). Dar es Salaam: Ministry of Education, Science, and Technology.

MoEST. (2017). Basic Education Statistics of Tanzania (BEST). Dar es Salaam: Ministry of Education, Science, and Technology.

MoEST. (2018). Basic Education Statistics of Tanzania (BEST). Dar es Salaam: Ministry of Education, Science, and Technology.

MoEST. (2019). Basic Education Statistics of Tanzania (BEST). Dar es Salaam: Ministry of Education, Science, and Technology.

MoEVT. (2010). Ministry of Education and Vocational Training. O-level Biology Syllabus for Secondary school. Form I-IV.

MoEVT. (2014a). Education and Training Policy. Dar es Salaam: Ministry of Education and Vocational Training.

MoEVT. (2014b). Basic Education Statistics in Tanzania. Dar es Salaam: Ministry of Education and Vocational Training.

Mozayan, M. R. (2015). BICS \& CALP Revisited: A Critical Appraisal. International Journal of Educational Investigations, 2(9), 103-111.

Ndalichako. J. L., \& Komba. A. A. (2014). Students' Subject Choice in Secondary Schools in Tanzania: A Matter of Students' Ability and Interests or Forced Circumstances? Open Journal of Social Sciences, 2, 4956. https:/ / doi.org/10.4236/jss.2014.28008
Orlich, D., C., Harder, R., J., Callahan, R., C. (2007). Teaching Strategies. A Guide to effective Instruction. Houghton: Mifflin Company.

Ricketts, A. (2014). Preservice elementary teachers' ideas about scientific practices. Science \& Education, 23(10), 2119-2135. https:/ / doi.org/10.1007/s11191014-9709-7

Roy-Campbell, Z. (1992). Power of pedagogy: choosing the medium on instruction in Tanzania. Madison: University of Wisconsin.

Rubagumya, C. (2003). English Medium Primary Schools in Tanzania: A New Linguistic Market in Education? In B. Brock-Utne, Z. Desai, \& M. Qorro (Eds), Language of Instruction in Tanzania and South Africa (LOITASA) (pp.149-170). Dar es Salaam: E \& D Limited. https://doi.org/10.1163/ 9789460912221005

Schweisfurth, M. (2013). Learner-Centred Education in International Perspective: Whose Pedagogy for Whose Development? Oxford: Routledge. https://doi.org/ 10.4324/9780203817438

Semali, L. M., \& Mehta (2012). Science education in Tanzania: Challenges and policy responses. International Journal of Educational Research, 53(2012), 225-239. https://doi.org/10.1016/j.ijer. 2012.03.012

Shohamy, E., Gordon, C. M., \& Kraemer, R. (1992). The effects of raters' background and training of the reliability of direct writing tests. The modern Language Journal, 76(1), 27-33. https://doi.org/ $10.2307 / 329895$

Swain, M. (2000). The Output Hypothesis and Beyond: Mediating Acquisition through Collaborative Dialogue. In J. P. Lantolf (Ed.), Sociocultural Theory and Second Language Learning (pp. 97-114). New York: Oxford University Press.

Thaiposri, P., \& Wannapiroon, P. (2015). Enhancing Students' Critical Thinking Skills throughTeaching and Learning by Inquiry-based Learning Activities Using Social Network and Cloud Computing. Procedia - Social and Behavioral Sciences, 174, 21372144. https:// doi.org/10.1016/j.sbspro.2015.02.013

Vygotsky, L. S. (1962). Thought and Language. New York: Wiley. https:/ / doi.org/10.1037/11193-000

Vygotsky, L. S. (1978). Mind and society: The development of higher psychological processes. Harvard University.

Wells, G. (1999). Dialogic Inquiry: Toward a Sociocultural Practice and Theory of Education. Cambridge University Press. https://doi.org/10.1017/ CBO9780511605895

Yang, H. A. (2017). Research on The Effective Questioning Strategies in Class Science Journal of Education, 54(158), 10-18. https:/ / doi.org/10.11648 /j.sjedu.20170504.16 


\section{APPENDIX 1}

$\underline{\text { Scores of Pedagogical Language Strategy Indicators Before Intervention }}$

\section{No \\ Pedagogical language strategy indicators}

SOB 1 SOB 2 SOB 3 standard deviation

\begin{tabular}{lclllc} 
& & & & and significance \\
\hline 1 & Teacher sets competencies to achieve in class & 4 & 4 & 4 & $4.0 \pm 0.0^{\mathrm{a}}$ \\
\hline 2 & Teacher sets language objectives to achieve in class & 0 & 0 & 0 & $0.0 \pm 0.0^{\mathrm{a}}$ \\
\hline 3 & Teacher sets activities to reinforce competences & 3 & 3 & 3 & $3.0 \pm 0.0^{\mathrm{a}}$ \\
\hline 4 & $\begin{array}{c}\text { Teacher provides the ways that are able to encourage learners to } \\
\text { answer in English through questioning }\end{array}$ & 0 & 0 & 0 & $0.0 \pm 0.0^{\mathrm{a}}$ \\
\hline 5 & $\begin{array}{c}\text { Teacher provides different techniques to rise questions that are asked } \\
\text { in English from learners }\end{array}$ & 0 & 0 & 0 & $0.0 \pm 0.0 \mathrm{a}$ \\
\hline
\end{tabular}

Teacher demonstrates ability to link the present subject with the

6 previous learning in a proper and clear English adapted to the level of $\begin{array}{llllll}0 & 0 & 0 & 0.0 \pm 0.0 \text { a }\end{array}$ learners

\begin{tabular}{|c|c|c|c|c|c|}
\hline 7 & Teacher draws from students' prior knowledge & 4 & 4 & 3 & $3.6 \pm 0.6^{a}$ \\
\hline 8 & Teacher engages all students in classroom interactions & 0 & 0 & 0 & $0.0 \pm 0.0^{\mathrm{a}}$ \\
\hline 9 & Uses different activities to enhance learning of the subject knowledge & 0 & 0 & 0 & $0.0 \pm 0.0^{a}$ \\
\hline 10 & Teacher sets the strategies to develop the English writing skills & 1 & 1 & 1 & $1.0 \pm 0.0^{a}$ \\
\hline 11 & Teacher sets the strategies to develop the English-speaking skills & 0 & 0 & 1 & $0.3 \pm 0.6^{a}$ \\
\hline 12 & Teacher sets the strategies to develop the English reading skills & 1 & 0 & 0 & $0.3 \pm 0.6^{\mathrm{a}}$ \\
\hline 13 & Teacher sets the strategies to develop the English listening skills & 0 & 0 & 1 & $0.3 \pm 0.6^{\mathrm{a}}$ \\
\hline 14 & Teacher corrects and orients students' feedback using clear English & 0 & 1 & 0 & $0.3 \pm 0.6^{\mathrm{a}}$ \\
\hline 15 & Teacher helps students to clarify ideas in English & 0 & 0 & 1 & $0.3 \pm 0.6^{\mathrm{a}}$ \\
\hline 16 & Teacher guides students to use appropriate terminology & 0 & 0 & 1 & $0.3 \pm 0.6^{a}$ \\
\hline 17 & $\begin{array}{l}\text { Teacher asks students to make group discussions and report back to } \\
\text { class }\end{array}$ & 4 & 3 & 2 & $3.0 \pm 1.0^{a}$ \\
\hline 18 & $\begin{array}{l}\text { Teacher allows students to use simple sentences to report their } \\
\text { answers in English }\end{array}$ & 0 & 0 & 0 & $0.0 \pm 0.0 \mathrm{a}$ \\
\hline 19 & Students share the thoughts with each other in English & 0 & 0 & 0 & $0.0 \pm 0.0^{a}$ \\
\hline 20 & Students engage actively in both content-language based tasks & 1 & 1 & 1 & $1.0 \pm 0.0^{\mathrm{a}}$ \\
\hline 21 & $\begin{array}{c}\text { Students appropriately use the provided language supportive } \\
\text { resources i.e glossary }\end{array}$ & 1 & 1 & 1 & $1.0 \pm 0.0^{a}$ \\
\hline 22 & Students complete the provided tasks in a given time & 1 & 1 & 1 & $1.0 \pm 0.0^{\mathrm{a}}$ \\
\hline 23 & Students gives oral presentation after the discussed topic in English & 3 & 4 & 3 & $3.3 \pm 0.6^{a}$ \\
\hline 24 & $\begin{array}{l}\text { Teacher allows students to use simple sentences to report their } \\
\text { answers in English }\end{array}$ & 1 & 1 & 1 & $1.0 \pm 0.0 \mathrm{a}$ \\
\hline 25 & $\begin{array}{c}\text { Majority students are comfortable with the teaching methodology } \\
\text { Clarity of content-language teaching resources }\end{array}$ & 1 & 1 & 1 & $1.0 \pm 0.0^{a}$ \\
\hline 26 & Majority of tasks completion in a given time & 1 & 1 & 1 & $1.0 \pm 0.0^{\mathrm{a}}$ \\
\hline 27 & Students ability to respond to asked subject-questions in English & 1 & 1 & 1 & $1.0 \pm 0.0^{a}$ \\
\hline 28 & $\begin{array}{c}\text { Exercise provided as learner evaluation by the teacher reinforces both } \\
\text { English and subject mastery (problem solving) skills }\end{array}$ & 1 & 1 & 1 & $1.0 \pm 0.0^{a}$ \\
\hline & Total scores & & & & $0.9 \pm 0.2^{a}$ \\
\hline
\end{tabular}

Note: SOB: Scores from the observers, a: significant differences $(\mathrm{P}<0.05)$ 


\section{APPENDIX 2}

Changes in Development of Pedagogical Language Strategy Indicators After the Intervention

\begin{tabular}{|c|c|c|c|c|c|c|c|}
\hline $\begin{array}{l}\text { S/ } \\
\text { No }\end{array}$ & Pedagogical language strategy indicators & $\begin{array}{c}\text { MSLO } \\
2\end{array}$ & $\begin{array}{c}\text { MSLO } \\
3\end{array}$ & $\begin{array}{c}\text { MSLO } \\
4\end{array}$ & $\begin{array}{c}\text { MSLO } \\
5\end{array}$ & $\begin{array}{c}\text { MSLO } \\
6\end{array}$ & $\begin{array}{l}\text { Overall Mean } \pm \\
\text { SD, and } P \text { value }\end{array}$ \\
\hline 1 & Teacher sets competencies to achieve in class & $\begin{array}{l}3.0 \pm \\
0.0^{\mathrm{a}}\end{array}$ & $4 \pm 0.1^{\mathrm{a}}$ & $4 \pm 0.1^{\mathrm{a}}$ & $4 \pm 0.1^{\mathrm{a}}$ & $4 \pm 0.1^{\mathrm{a}}$ & $3.8 \pm 0.4^{\mathrm{a}}$ \\
\hline 2 & Teacher sets language objectives to achieve in class & $1 \pm 0.1^{\mathrm{a}}$ & $4 \pm 0.3^{\mathrm{a}}$ & $4 \pm 0.3^{a}$ & $4 \pm 0.3^{a}$ & $4 \pm 0.3^{a}$ & $3.4 \pm 1.3^{\mathrm{a}}$ \\
\hline 3 & Teacher sets activities to reinforce competences & $2 \pm 0.2^{\mathrm{a}}$ & $3 \pm 0.1^{\mathrm{a}}$ & $3 \pm 0.1^{\mathrm{a}}$ & $4 \pm 0.2^{\mathrm{a}}$ & $4 \pm 0.2^{\mathrm{a}}$ & $3.2 \pm 0.8^{\mathrm{a}}$ \\
\hline 4 & $\begin{array}{c}\text { Teacher provides the ways that are able to encourage learners to } \\
\text { answer in English through questioning }\end{array}$ & $1 \pm 0.1^{\mathrm{a}}$ & $2 \pm 0.1^{\mathrm{a}}$ & $2 \pm 0.1^{\mathrm{a}}$ & $2 \pm 0.1^{\mathrm{a}}$ & $3 \pm 0.3^{\mathrm{a}}$ & $2.0 \pm 0.7 \mathrm{a}$ \\
\hline 5 & $\begin{array}{c}\text { Teacher provides different techniques to rise questions that are } \\
\text { asked in English from learners }\end{array}$ & $2 \pm 0.1^{\mathrm{a}}$ & $2 \pm 0.1^{\mathrm{a}}$ & $4 \pm 0.3^{\mathrm{a}}$ & $3 \pm 0.2^{\mathrm{a}}$ & $4 \pm 0.3^{\mathrm{a}}$ & $3.0 \pm 1.0^{\mathrm{a}}$ \\
\hline
\end{tabular}

Teacher demonstrates ability to link the present subject with the

6 previous learning in a proper and clear English adapted to the $1 \pm 0.1^{\mathrm{a}} 1 \pm 0.1^{\mathrm{a}} 2 \pm 0.3^{\mathrm{a}} 2 \pm 0.3^{\mathrm{a}} \quad 4 \pm 0.4^{\mathrm{a}} \quad 2.0 \pm 1.2^{\mathrm{a}}$ level of learners

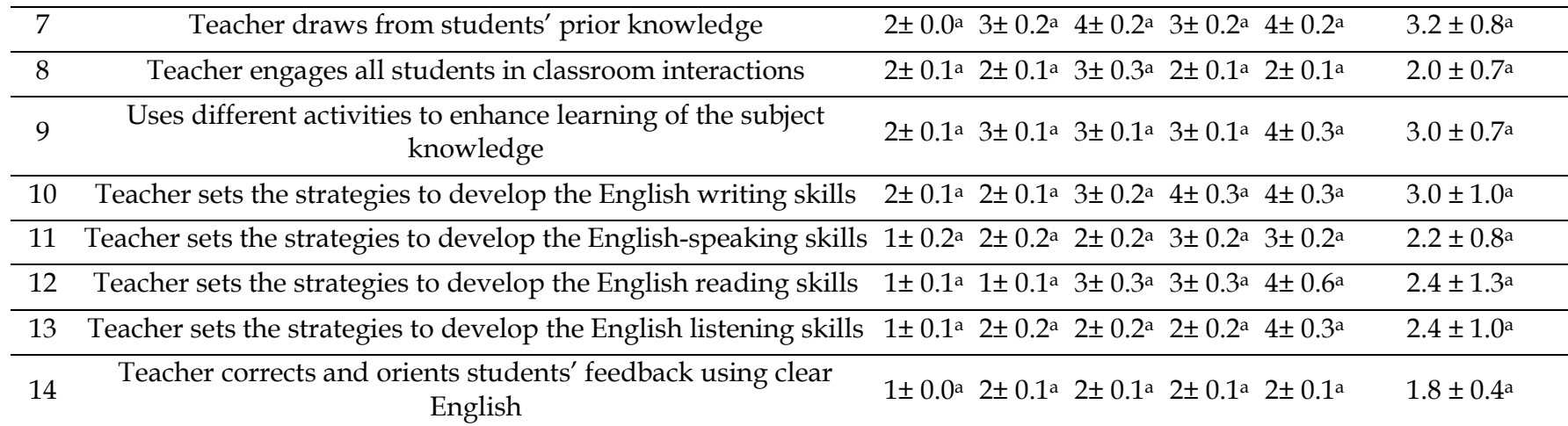

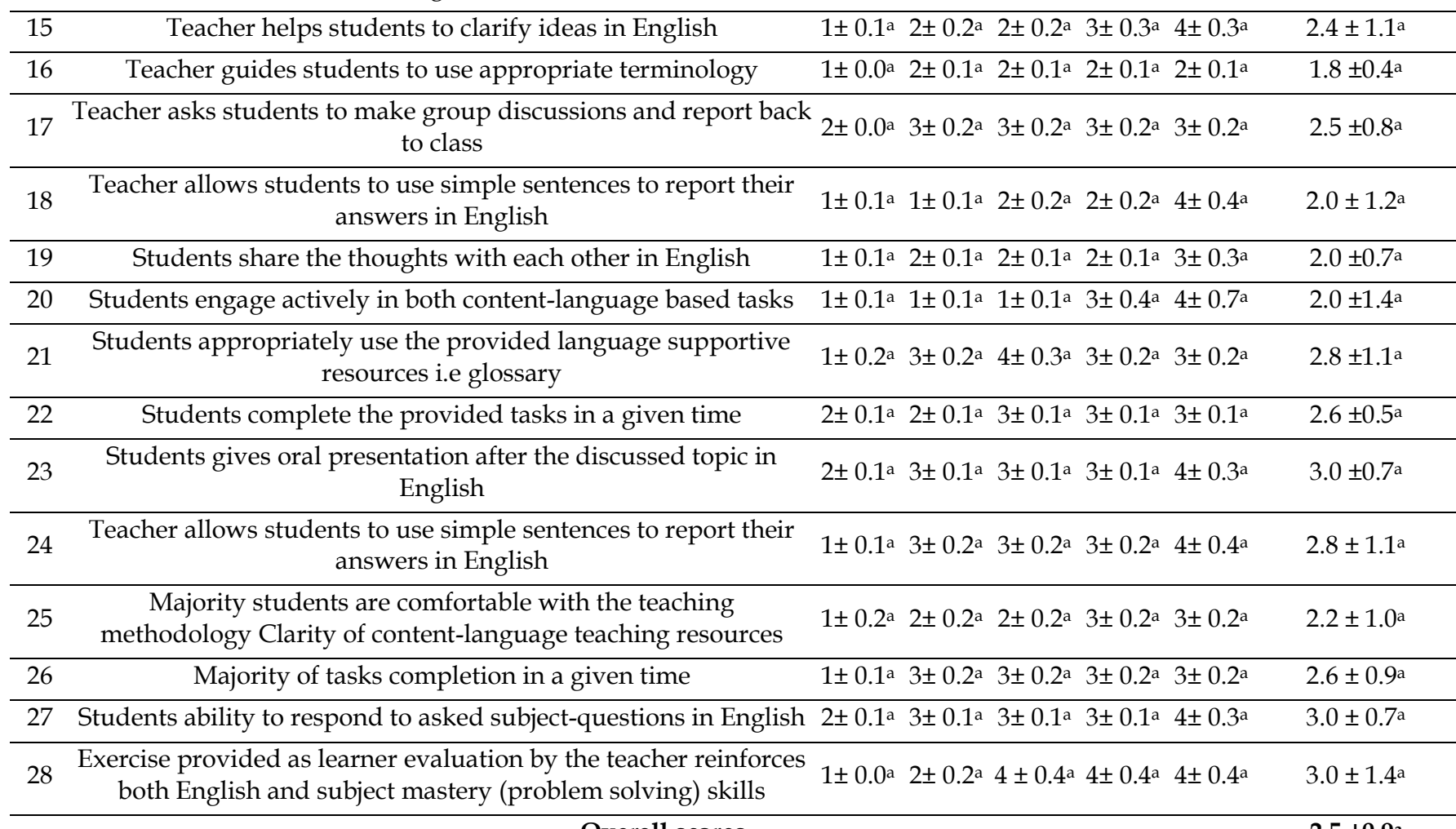

MSLO: mean scores in lesson observation, SD: standard deviation, a: significant difference $(\mathrm{P}<0.05)$ 


\section{APPENDIX 3}

\section{Data Collection Tools}

Dates: ...................../ 2020

Teacher's ID ........................School ID

District

Region

Topic.

Class/Stream

Duration.

(mins.)

\section{PART A: CLASSROOM OBSERVATION CHECKLIST}

Note: Tick accordingly or cross through (0-not evident to 4-frequent evident)

\begin{tabular}{ll}
\hline Pedagogical language strategies Indicators & $\begin{array}{r}\text { Specific } \\
\text { examples }\end{array}$ \\
\hline Lesson plan & $0 \ldots \ldots 1 \ldots 2 \ldots 3 \ldots 4 \ldots \ldots \ldots$ \\
\hline Teacher: & $0 \ldots \ldots .1 \ldots 2 \ldots 3 \ldots 4 \ldots \ldots$ \\
1. Sets competencies to achieve in class & $0 \ldots \ldots 1 \ldots 2 \ldots . \ldots 4 \ldots \ldots \ldots$ \\
2. Sets language objectives to achieve in class & \\
3. Sets activities to reinforce competences &
\end{tabular}

Teacher:

4. Teacher provides the ways that are able to encourage learners to answer in English through questioning

$0 \ldots . . . .2 \ldots . . . .4 \ldots \ldots \ldots$

5. Teacher provides different techniques to rise questions that are asked in English from learners

$0 \ldots . .1 \ldots 2 \ldots . . . .4 \ldots \ldots . .$.

6.Teacher demonstrates ability to link the present subject with the previous learning in a proper and clear English

adapted to the level of leaners

$0 \ldots \ldots 1 \ldots 2 \ldots 3 \ldots . \ldots \ldots \ldots$

7. Teacher draws from students' prior knowledge

$0 \ldots . .1 \ldots 2 \ldots 3 \ldots 4 \ldots \ldots$.

8. Teacher engages all students in classroom interactions

$0 \ldots \ldots 1 \ldots 2 \ldots 3 \ldots 4 \ldots \ldots \ldots$

9.Teacher uses different activities to enhance learning of the subject knowledge

$0 \ldots \ldots 1 \ldots 2 \ldots 3 \ldots 4 \ldots \ldots \ldots$

Teaching and Learning Activities

Teacher gives activities that reinforce:

10. English writing skills

$0 \ldots \ldots 1 \ldots 2 \ldots 3 \ldots . \ldots 4 \ldots \ldots$

11. English speaking skills

$0 \ldots \ldots 1 \ldots 2 \ldots 3 \ldots 4 \ldots \ldots \ldots$

12. English reading skills

$0 \ldots \ldots 1 \ldots 2 \ldots 3 \ldots 4 \ldots \ldots \ldots$

13. English listening skills

$0 \ldots \ldots 1 \ldots 2 \ldots 3 \ldots 4 \ldots \ldots \ldots$

Language guidance

Teacher is able to:

14. Correct and orient students' feedback using clear

15. Help students to clarify ideas in English

$0 \ldots \ldots 1 \ldots 2 \ldots . . . .4 \ldots \ldots \ldots$

16. Guide students to use appropriate terminology

$0 \ldots . .1 \ldots 2 \ldots 3 \ldots 4 \ldots \ldots \ldots$

17. Ask students to make group discussions and report back to class.

$0 \ldots \ldots 1 \ldots 2 \ldots 3 \ldots . \ldots \ldots \ldots$

18. Teacher allows students to use simple sentences to report their answers in English

$0 \ldots \ldots 1 \ldots 2 \ldots 3 \ldots 4 \ldots \ldots$.

19. Provide clear instruction about the experiment

$0 \ldots \ldots 1 \ldots 2 \ldots 3 \ldots . \ldots \ldots \ldots$

Students' participation in the lesson s' learning

During the group discussion:

20. Students share the thoughts with each other in English

$0 \ldots \ldots 1 \ldots 2 \ldots 3 \ldots 4 \ldots \ldots \ldots$

21.Students engage actively in both content-language based tasks

$0 \ldots \ldots 1 \ldots 2 \ldots 3 \ldots . \ldots \ldots \ldots$

22. Students appropriately use the provided language supportive resources i.e glossary in English

23. Students complete the provided tasks in a given time

$0 \ldots . . . .2 \ldots 3 \ldots 4 \ldots \ldots$.

24. Students give oral presentation after the discussed topic in English Evident

$0 \ldots \ldots 1 \ldots 2 \ldots 3 \ldots . \ldots \ldots \ldots$

Inquiry process (problem solving/mastery of subject)

25. Majority students comfortable with the teaching methodology Clarity of content-language teaching resources

26. Majority of tasks completion in a given time

$0 \ldots \ldots 1 \ldots 2 \ldots 3 \ldots . . \ldots \ldots \ldots$

27. Students ability to respond to asked subject-questions in English

$0 \ldots \ldots 1 \ldots 2 \ldots 3 \ldots . \ldots \ldots \ldots$

28. Exercise provided as learner evaluation by the teacher reinforces both English and subject mastery skills

$0 \ldots . .1 \ldots 2 \ldots 3 \ldots . \ldots \ldots \ldots$ 


\section{Inquiry based Learning Activities Evaluation}

\begin{tabular}{lll}
\hline Phase & Activity & $\begin{array}{l}\text { Frequent } \\
\text { evident/Not } \\
\text { Evident }\end{array}$ \\
\hline Engagement & & \\
\hline $\begin{array}{l}\text { Teacher gains students' interests by using short (4mins) activities or } \\
\text { examples through variety of teaching aids that link to the prior } \\
\text { knowledge using English language Evident }\end{array}$ & $\begin{array}{l}\text { Physical appearance of } \\
\text { organisms, i.e. shape }\end{array}$ & $0 \ldots . . . .2 \ldots 3 \ldots . \ldots$ \\
\hline Exploration & & \\
\hline
\end{tabular}

\section{Exploration}

Students clarify their understanding by setting up the hypotheses through English language

Students compose questions that $0 \ldots \ldots 1 \ldots 2 \ldots 3 \ldots 4 \ldots$ require answers

\section{Explanation}

Students provide interpretations and draw the conclusions from set of Presenting their findings / activities provided using proper English observations

\section{Elaboration}

Teacher provide new questions to help students apply their knowledge

The teacher asking questions that $0 \ldots \ldots 1 \ldots 2 \ldots 3 \ldots . \ldots$ lead to identifying the areas of concentration that students appear to miss them.

\section{Evaluation}

Students assess themselves and the teacher provide the exercise
$0 \ldots \ldots 1 \ldots 2 \ldots 3 \ldots . . .$. and the exercise

\section{PART B: STUDENTS ENGLISH WRITING AND READING SKILLS EVALUATION}

\section{Content questions about invertebrates for students to perform after the end of lesson}

A teacher will prepare questions based on Bloom's taxonomy prior to the class sessions with a marking scheme. Questions will base on the lesson of the day with reference to the unit of invertebrates. The evaluation of the leaners' performance will focus on:

(a) The correctness of answers

(b) Coverage of the language skills as per tables below:

Appendix 3.1. Criteria, Category, and Ranking for Language Writing Skills Evaluation Process

\begin{tabular}{|c|c|c|}
\hline Criteria & Category & Rank \\
\hline A paragraph without errors in vocabulary, syntax, grammar, and morphology & Accurate & 4 \\
\hline A paragraph without errors in vocabulary, syntax, grammar, but have in morphology & Fairly accurate & 3 \\
\hline A paragraph without errors in vocabulary, syntax, morphology but have in grammar & Poor & 2 \\
\hline A paragraph without errors in, syntax, morphology but have in grammar and vocabulary & Very poor & 1 \\
\hline A paragraph with errors in syntax, morphology, grammar, and vocabulary & No accuracy & 0 \\
\hline
\end{tabular}

\section{Throughout the lesson}

Appendix 3.2. Language reading skills evaluation process

\begin{tabular}{|c|c|c|}
\hline Criteria & Category & Rank \\
\hline The reading is adhering to spelling, pronunciation marks, commas, and full stop & Accurate & 4 \\
\hline The reading is adhering to spelling pronunciation marks but it does not respect commas and full stop & fairly accurate & 3 \\
\hline $\begin{array}{l}\text { The reading is adhering to spelling but it does not pay attention on pronunciation, and does not respect } \\
\text { commas and full stop }\end{array}$ & Poor & 2 \\
\hline $\begin{array}{l}\text { The reading is completely not adhering and respecting neither spelling nor pronunciation, commas and } \\
\text { full stops }\end{array}$ & Very poor & 1 \\
\hline The student completely failed to read the sentence & No accuracy & 0 \\
\hline
\end{tabular}




\section{PART C: STUDENTS FOCUS GROUP DISCUSSION TOPICS}

1. What did you learn in the lesson of today?

2. What specifically did you like about the lesson of today?

3. How the teaching methodology (style) during the lesson helped you in learning new things?

4. Did you find any difficulties in learning some of the concepts in today's lesson?

\section{PART D: INTERVIEW SCHEDULE FOR TEACHERS}

5. Do you face any teaching difficulties associated with both pedagogy and language of instruction? (Yes/No)

6. If yes, can you mention those associated with pedagogy (instructional strategy) and those associated with the language of instruction?

(a) Instructional strategy

i.

ii.

iii.

iv.

(b) Language of instruction

i

ii.

iii.

iv

7. What do you plan to do to address or cope with the mentioned difficulties? 
PART E: LESSON EVALUATION

8. How did you see the lesson of today?

9. What were the key issues that you think have to be addressed to improve the next lesson?

10. Observers comments to the teacher concerning the lesson about strong and points of improvement 


\section{APPENDIX 4}

\section{Sample Invertebrate Questions Used During Formative Assessments}

\section{INVERTEBRATES TEACHING AND LEARNING IN TANZANIA SECONDARY SCHOOLS}

\section{Biology session}

Class: Form 4 (secondary school)

Topic: Kingdom Animalia

Sub-topic: Phylum Platyhelminthes

Exercise

Questions with expected answers from students:

\section{Comprehension (Understanding)}

Concisely (in not more than 6 sentences with one example) distinguish between the general and distinctive features of the phylum Platyhelminthes (1 Mark)

Ans: General characteristics are the features that apply to the entire phylum and they represent the respective Phylum/Kindom for example being Acoelomate and triploblastic with incomplete gut in this case. However, distinctive characteristics are those features which distinguish the classes, phylum Platyhelminthes in this case, for example habitat and presence of body structures such as cilia.

2. Application (context different than one in which it was learned)

What facts would you select to prove the adaptation of Planaria to live in the body of its host? (2 Marks)

Ans: Planaria adapts to its host cells through cilia for attachment to the lining of small intestine and propel food. They are small and slander for absorption of nutrients.

3. Analysis (break material into parts and show how it is put together)

What is the taxonomic relationship between class Trematoda and Cestoda? (Answer in only one paragraph of not more than five sentences) (3 Marks)

Ans: Both have sense organs concentrated in the head region, acoelomates, tripoblastic, body can be divided along only 1 plane of symmetry to yield 2 mirror images of each other (enantiomers), incomplete gut, and the blastomere becomes the mouth.

\section{Synthesis}

What would you predict if animal in class tubelaria would not have cilia on the underside of their bodies? ( 3 Marks)

Ans: Cilia in tubelaria are highly conserved with 9+2 axoneme and a full complement of inner and outer dynein motors. The cilia are specifically for locomotion. Therefore, there would be no movement for these free living invertebrates and this could lead to their death as no food would be gathered. 


\section{APPENDIX 5}

Sample Revised Tanzania Secondary School Biology Teacher's Lesson Plan-2020

Name of Subject: Biology

Teacher's Name (code):

\begin{tabular}{|c|c|c|c|c|c|c|c|c|c|c|c|c|}
\hline Date & Class & Period & Time & \multicolumn{9}{|c|}{ Number of students } \\
\hline & \multirow[b]{2}{*}{ FORM-IV } & & \multirow[b]{2}{*}{80 (mins) } & \multicolumn{3}{|c|}{ Registered } & \multicolumn{3}{|c|}{ Present } & \multicolumn{3}{|c|}{ Absentees } \\
\hline & & & & $\mathrm{M}$ & $\mathrm{F}$ & $\mathrm{T}$ & $\mathrm{M}$ & $\mathrm{F}$ & $\mathrm{T}$ & $\mathrm{M}$ & $\mathrm{F}$ & $\mathrm{T}$ \\
\hline
\end{tabular}

Competence: At the end of lesson students should develop the ability to identify and explain both general and distinctive characteristics of classes under Phylum Platyhelminthes

Main topic: Kingdom Animalia

Sub-topic: Phylum Platyhelminthes (i.e Planaria, Flukes and Tape worms)

Main objective: To identify and explain both general and distinctive characteristics of classes under Phylum Platyhelminthes

Subject specific objectives: in the end of the lesson a student should be able to:

i. Identify the organisms under phylum Platyhelminthes

ii. Explain and distinguish the characteristics of organisms belong to each class in phylum Platyhelminthes

Language specific objective: in the end of the lesson a student should be able to:

i. Correctly read, pronounce, and write technical words

Teaching and learning materials:

English glossary of subject specific vocabulary, animal classification chart and cards, sample of live Platyhelminthes Reference: MoET Zanzibar (2009). Biology book 4. Dar-es-Salaam. Oxford University Press.

Lesson Development

\begin{tabular}{|c|c|c|c|c|}
\hline STAGES & $\begin{array}{l}\text { TIME } \\
\text { (Mins) }\end{array}$ & TEACHING ACTIVITIES & $\begin{array}{l}\text { LEARNING } \\
\text { ACTIVITIES }\end{array}$ & ASSESSMENT \\
\hline Introduction & 10 & $\begin{array}{l}\text { Start by asking students on daily } \\
\text { concepts about the economic } \\
\text { importance of animals under } \\
\text { kingdom Animalia }\end{array}$ & $\begin{array}{l}\text { Students to think, and } \\
\text { answer the questions }\end{array}$ & Oral questions \\
\hline $\begin{array}{l}\text { Development of } \\
\text { new knowledge }\end{array}$ & 30 & $\begin{array}{l}\text { Guide students to carry out the } \\
\text { experiment on identification of } \\
\text { organisms under phylum } \\
\text { Platyhelminthes }\end{array}$ & $\begin{array}{l}\text { students in groups to } \\
\text { carry out the } \\
\text { experiment following } \\
\text { scientific process steps }\end{array}$ & $\begin{array}{l}\text { Students: } \\
\text { Present the findings, } \\
\text { Answering questions from } \\
\text { audience and receive comments, } \\
\text { paraphrase the statements, and } \\
\text { clarify issues using proper English } \\
\text { language }\end{array}$ \\
\hline Reinforcement & 20 & $\begin{array}{l}\text { Organize students in groups to } \\
\text { revise and correct the mistakes }\end{array}$ & $\begin{array}{l}\text { Students in groups to } \\
\text { revise and correct the } \\
\text { mistakes as per the } \\
\text { teacher's and fellow } \\
\text { students' suggestions }\end{array}$ & $\begin{array}{l}\text { Students prepare newly revised } \\
\text { feedback from the activity to be } \\
\text { marked by the teacher }\end{array}$ \\
\hline Reflection & 10 & $\begin{array}{l}\text { Summarize learner's responses with } \\
\text { regard to daily life applications }\end{array}$ & Students to take notes & $\begin{array}{l}\text { Students submit their note to be } \\
\text { checked by the teacher }\end{array}$ \\
\hline Consolidation & 10 & Provide individual exercise & $\begin{array}{l}\text { Students to note down } \\
\text { the individual exercise } \\
\text { and work for it. }\end{array}$ & $\begin{array}{l}\text { Students provide answers and the } \\
\text { teacher marks to check the } \\
\text { correctness as per lesson objectives }\end{array}$ \\
\hline
\end{tabular}


Teacher's evaluation on overall students' engagement during the lesson

Teacher's evaluation against specific objectives

\section{Overall Remarks}


APPENDIX 6

Sample Writings of Students No. 200 at Cycle 4 (12/08/2020) and Cycle $6(14 / 09 / 2020)$

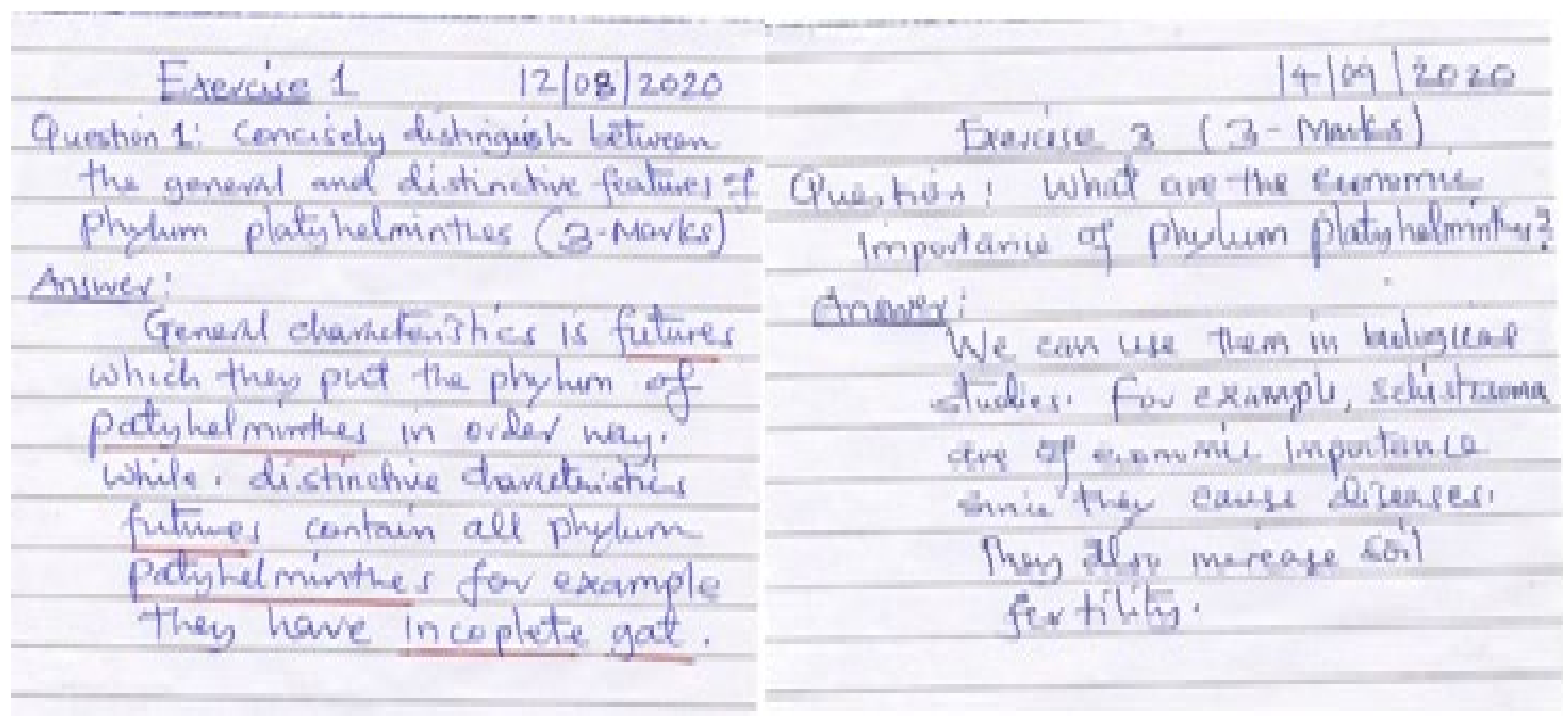

\section{http://www.ejmste.com}

